\title{
Factors Associated with County-Level Variation in the Prescription of Statins
}

\author{
Steph A. Karpinski, MS; Kevin A. Look, PhD; and David J. Vanness, PhD
}

\begin{abstract}
BACKGROUND: The American College of Cardiology/American Heart Association recommends statins for adults aged 40-75 years with a cardiovascular disease risk factor and a 10-year risk of cardiovascular events of $7.5 \%-19.9 \%$.

OBJECTIVE: To examine the association of county-level social determinant measures of health and composition of health services with use of statin prescriptions under Medicare Part D.

METHODS: We used 2013 Medicare Part D prescriber county-level data to construct 2 measures of statin use: (1) statin beneficiaries $\div$ total beneficiaries (prevalence $\left[\beta_{\mathrm{PR}}\right]$ ) and (2) statin days supplied $\div$ (total beneficiaries $\times 365$; adequacy of supply $\left.\left[\beta_{\mathrm{AS}}\right]\right)$. We used multivariable regression to estimate the association of each measure with county-level demographics and health service measures.
\end{abstract}

RESULTS: A 1 standard deviation (SD) increase in the proportion of African Americans living in a county is associated with a $0.096 \mathrm{SD}$ decrease in adequacy of supply $\left(\beta_{\mathrm{AS}}=-0.096 ; 95 \% \mathrm{Cl}=-0.14\right.$ to -0.06$)$. The proportion of county residents aged $65+$ years who are female was associated with higher prevalence and adequacy of supply $\left(\beta_{\mathrm{PR}}=0.06 ; 95 \% \mathrm{Cl}=0.02\right.$ to 0.11 ; $\beta_{A S}=0.09 ; 95 \% \mathrm{Cl}=0.05$ to 0.14$)$. Counties with higher proportions of Medicare Part $D$ prescription expenditures receiving low-income subsidies had lower adequacy of supply $\left(\beta_{\mathrm{AS}}=-0.28 ; 95 \% \mathrm{Cl}=-0.32\right.$ to -0.23$)$. Counties with a higher proportion of Medicare Part $D$ prescribers who are nurse practitioners was associated with lower prevalence and adequacy of supply $\left(\beta_{\mathrm{PR}}=-0.39\right.$; $95 \% \mathrm{Cl}=-0.44$ to $-0.35 ; \beta_{\mathrm{AS}}=-0.42 ; 95 \% \mathrm{Cl}=-0.47$ to -0.37$)$.

CONCLUSIONS: Race and ethnicity, income, and distribution of provider types were significantly associated with county-level variation in statin use, despite being unlikely to measure differences in actual medical need. Such variation more likely reflects predisposing and enabling factors potentially affected by social, economic, and public health policy. Tracking variation in county-level statin use associated with these factors could help policymakers assess progress in reducing health care disparities and better target program resources.

J Manag Care Spec Pharm. 2019;25(12):1358-65

Copyright $\odot 2019$, Academy of Managed Care Pharmacy. All rights reserved.

\section{What is already known about this subject}

The American College of Cardiology/American Heart Association recommends statins for adults aged 40-75 years with a cardiovascular disease risk factor and a 10-year risk of cardiovascular events of $7.5 \%-19.9 \%$.

In U.S. survey and self-reported data, statin use varies by race and ethnicity, income, and gender at the individual level.

\section{What this study adds}

County-level Medicare Part D statin prescription rates vary by county-level measures of race and ethnicity, with lower adequacy of supply (statin prescription days per beneficiary day) in counties with a higher proportion of residents who are black or African American (standardized $\beta=-0.096$ ), Hispanic/Latino (standardized $\beta=-0.084$ ), or American Indian/Alaskan Native (standardized $\beta=-0.102$ )

Adequacy of supply is lower in counties with higher proportions of uninsured residents (standardized $\beta=-0.202$ ) and where a higher proportion of county-level Medicare Part D drug costs are eligible for low-income subsidy (standardized $\beta=-0.276$ )

Counties with a higher proportion of prescribing providers who are nurses (standardized $\beta=-0.418$ ) or physician assistants (standardized $\beta=-0.379$ ) have lower adequacy of supply.

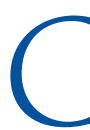
ardiovascular disease is the leading cause of mortality in the United States. ${ }^{1}$ The United States Preventive Services Task Force currently recommends statins for adults aged 40-75 years with at least 1 cardiovascular disease risk factor and a 10-year risk of cardiovascular events of $\geq 10 \%$, while the American College of Cardiology/American Heart Association (ACC/AHA) currently recommends statins for adults with risk of atherosclerotic cardiovascular disease as low as $7.5 \%$ after a clinician-patient risk discussion. ${ }^{2,3}$

Previous studies have shown differences in statin use by race and ethnicity, gender, and class. Specifically, nonwhites and Hispanics/Latinos are less likely to use statins than nonHispanic/Latino whites; women are less likely to use statins than men; and those with lower incomes are less likely to use statins than those with higher incomes. ${ }^{4-8}$ Adopting the terminology of Andersen's behavioral model of health services use, ${ }^{9}$ to the extent that observed differences are a result of predisposing and enabling factors such as race and ethnicity, gender, and socioeconomic class rather than medical need, such differences may indicate disparities.

If national individual-level survey evidence holds true more generally, we would expect to find confirmatory evidence in national prescription data. Therefore, we used an ecological model to examine associations between social determinants of health $(\mathrm{SDOH})$ and Medicare Part D statin prescription rates at the U.S. county level in 2013, which serves as an 
important baseline year for comparison, since ACC/AHA guidelines issued that year expanded the population considered appropriate for primary prevention with statins to an estimated one third of U.S. adults. ${ }^{10}$

Our primary objective for this study was to examine the association of variables related to race and ethnicity, gender, and class with statin prescription. The secondary objective was to explore the effects of predisposing and enabling covariates for hypothesis generation.

\section{Methods}

\section{Data Sources}

We obtained data on prescription drugs prescribed by physicians and other health care providers that were paid under the Medicare Part D prescription drug program from the 2013 Medicare Part D Prescriber Public Use File. ${ }^{11}$ Provider summary and drug detail files included total beneficiaries, costs, claims, and days supply by drug category for each provider, as well as general provider information. ${ }^{12}$ Prescriptions for Part D prescribers that were filled under low-cost retail pharmacy programs outside of Part D were not captured.

We compiled a list of heart-related medications from the literature. ${ }^{14,15}$ We then selected providers in the continental United States who had prescribed a heart-related medication, had credential and specialty information indicating work in a primary care function, and who were listed as either an MD or DO, a prescribing nurse, or a physician assistant. To assign providers to counties, we compiled a list of provider ZIP codes spanning more than 1 county, using the U.S. Census 2010 ZIP Code Tabulation Area Relationship File. ${ }^{16}$ For ZIP codes contained within 1 county, we used the sashelp.zip table (listing the primary county for each ZIP code) to assign provider county. For providers in ZIP codes spanning multiple counties, we used the Texas A\&M University (TAMU) geocoder. ${ }^{17}$

\section{Dependent Variables}

We derived 2 county-level statin utilization dependent variables: Statin prescription prevalence $\left(\beta_{\mathrm{PR}}\right)$ was defined as the number of Part $\mathrm{D}$ beneficiaries in a county receiving statins divided by the total number of county Part D beneficiaries; statin adequacy of supply $\left(\beta_{\mathrm{AS}}\right)$ was defined as the sum of days supply of statins to Part D beneficiaries within a county divided by the total number of Part D beneficiaries within a county, multiplied by 365 . We included the latter measure to better incorporate continuity of treatment. ${ }^{13}$

\section{Covariates}

County-level covariates were derived from a variety of sources, including the 2015 County Health Rankings (CHR), which comprises various secondary sources mostly from 2013. ${ }^{18,19}$ Other data sources included American Fact Finder, ${ }^{20}$ the Centers for Medicare \& Medicaid Services (CMS) Open Payments List of
Teaching Hospitals, ${ }^{21}$ Medicare Part D Enrollment Dashboard data, and Medicare Geographic Variation Public Use File. 22-24 We selected covariates in 2 stages. First, we assessed validity for inclusion among variables representing similar constructs by using theoretical considerations and reviewing the statin prescription literature. Second, we excluded potential covariates if they significantly increased the variance inflation index or significantly reduced the number of counties available for analysis. When possible, we replaced variables reducing the number of observations with comparable covariates that did not reduce the number of observations. The data sources for all covariates are given in Table 1.

Covariates to test the main hypotheses included the proportion of county residents who identify according to U.S. Censusbased race categories (Black or African American, American Indian or Alaska Native, Asian, and Native Hawaiian or Pacific Islander) and Hispanic or Latino ethnicity. We included the proportions of all county residents and of residents aged 65 years and over who were female because potential sex-related differences in cardiovascular mortality could alter county gender composition. ${ }^{25}$ Covariates related to socioeconomic class included median household income in U.S. dollars, the proportion of county residents who were uninsured, the proportion unemployed, and the proportion of county Medicare Part D prescription total costs covered under Medicare Part D low-income subsidies. Other predisposing contextual factors included proportions of county residents living in a rural area, the proportion aged 65 years and older, the proportion not proficient in English, the number of social associations (membership organizations) per 10,000 population, ${ }^{26}$ and the proportion of residents who attended at least some college.

Covariates related to health services delivery enabling factors included the proportion of selected prescribing providers who were doctors (MD or DO), nurses, or physician assistants and the proportion who were female. We also included the rate of primary care physicians per 100,000 population, the number of primary care physicians per Part D beneficiary, proportion of Medicare Part D prescription costs that were generic, proportion of Medicare Part D prescription costs that were through Medicare Advantage, and Medicare Part D enrollment. To estimate county-level access to teaching hospitals, we calculated the average distance between the geographic coordinates of each county ZIP code centroid to the coordinates of the addresses of teaching hospitals listed in the CMS Open Payments List of Teaching Hospitals.

Finally, we included county-level average Hierarchical Condition Category (HCC) risk scores from 2013 Medicare geographic variation data, ${ }^{23,24}$ as well as the proportion of county residents who self-reported being physically inactive or diabetic as factors that may be related to actual medical need for statins. 
TABLE 1 Variables Included in the County-Level Analysis that Explored Primary Care Statin Prescription Prevalence and Adequacy of Supply in 2013 Medicare Part D Providers

\begin{tabular}{|c|c|c|}
\hline Variable $\left(N=3,029^{a}\right)$ & Calculation Within the Dataset (If Applicable) & Mean (SD) \\
\hline \multicolumn{3}{|l|}{ Dependent variables } \\
\hline Statin prescription prevalence ${ }^{b}(n=2,994)$ & Statin beneficiaries in county $\div$ total beneficiaries in county & $0.241 \quad(0.063)$ \\
\hline Statin adequacy of supplyb $(n=2,994)$ & $\begin{array}{l}\text { Sum (statin day supply in county) } \div \text { (total beneficiaries in } \\
\text { county } \times 365)\end{array}$ & $0.153 \quad(0.044)$ \\
\hline \multicolumn{3}{|l|}{ Covariates related to main hypotheses } \\
\hline Proportion black or African American ${ }^{c}$ & & $0.091 \quad(0.144)$ \\
\hline Proportion American Indian or Alaska Native ${ }^{c}$ & & $0.019 \quad(0.065)$ \\
\hline Proportion Asianc $^{c}$ & & $0.013 \quad(0.022)$ \\
\hline Proportion Native Hawaiian or other Pacific Islanderc & & $0.001 \quad(0.001)$ \\
\hline Proportion Hispanic or Latinoc & & $0.088 \quad(0.133)$ \\
\hline Proportion female & & $0.5 \quad(0.022)$ \\
\hline Proportion females in $65+$ age group ${ }^{d}$ & \# females $65+$ in county $\div \# 65+$ in county & $0.554 \quad(0.027)$ \\
\hline County median income $e^{c}, \$$ & & $45,832(11,584)$ \\
\hline Proportion uninsuredc & & $0.212 \quad(0.064)$ \\
\hline Proportion unemployedc & & $0.073 \quad(0.026)$ \\
\hline Fraction of drug costs prescribed as generic ${ }^{b}(n=3,027)$ & Generic drug costs in county $\div$ total drug costs in county & $0.299 \quad(0.043)$ \\
\hline Fraction of drug costs prescribed under LIS $(n=3,028)$ & LIS drug costs in county $\div$ total drug costs in county & $0.538 \quad(0.141)$ \\
\hline Fraction of drug costs prescribed under MAPD plans ${ }^{b}(n=3,016)$ & MAPD costs in county $\div$ total drug costs in county & $0.207 \quad(0.139)$ \\
\hline \multicolumn{3}{|l|}{ Control variables } \\
\hline Proportion female providers ${ }^{b}$ & \# female providers in county $\div$ \# total providers in county & $0.494 \quad(0.169)$ \\
\hline Proportion doctors ${ }^{b}$ & \# doctors in county $\div$ \#total providers in county & $0.6 \quad(0.194)$ \\
\hline Proportion nurses ${ }^{b}$ & \# nurses in county $\div$ \# total providers in county & $0.266 \quad(0.185)$ \\
\hline Proportion physician assistants ${ }^{b}$ & \# physician assistants in county $\div$ \# total providers in county & $0.134 \quad(0.159)$ \\
\hline Proportion living in a rural areac & & $0.576 \quad(0.311)$ \\
\hline Proportion aged over 65 years ${ }^{c}$ & & $0.172 \quad(0.043)$ \\
\hline Proportion non-English speakers ${ }^{c}$ & & $0.018 \quad(0.029)$ \\
\hline Proportion inactive ${ }^{\mathrm{c}}$ & & $0.27 \quad(0.053)$ \\
\hline Proportion obese ${ }^{c}$ & & $0.307 \quad(0.044)$ \\
\hline Proportion diabetic ${ }^{c}$ & & $0.11 \quad(0.023)$ \\
\hline Rate of primary care physicians per 100,000 populationc $^{c}(n=2,919)$ & & $55.848(33.671)$ \\
\hline Proportion with at least some college ${ }^{c}$ & & $0.556 \quad(0.114)$ \\
\hline Rate of social associations per 10,000 population ${ }^{c}$ & & $13.884 \quad(6.884)$ \\
\hline Medicare Part D enrollment counte $(n=3,027)$ & & $11,523(32,998)$ \\
\hline Average Medicare risk score ${ }^{\mathrm{f}}(\mathrm{n}=3,027)$ & & $0.947 \quad(0.095)$ \\
\hline Average distance in miles to nearest teaching hospitals & $\begin{array}{l}\text { Sum (distance in miles from county provider's ZIP code } \\
\text { centroid to the nearest teaching hospital) } \div \# \text { providers in county }\end{array}$ & $\begin{array}{l}23.349 \text { miles } \\
(23.871)\end{array}$ \\
\hline $\begin{array}{l}\text { Fraction of Part D prescribing doctors over the number of Part D } \\
\text { enrollees }(n=3,027)\end{array}$ & $\begin{array}{l}\text { \# Primary care providers who are doctors in county } \div \text { \# Part D } \\
\text { enrollees in county }\end{array}$ & $0.004 \quad(0.003)$ \\
\hline
\end{tabular}

aUnless otherwise indicated.

bSourced or calculated from Part D Prescriber Data 2013.11

cSourced from County Health Rankings 2015.18,19

dSourced from the American Community Survey 2009-2013.20

eSourced from Medicare Program Statistics Enrollment Dashboard Data File 2013.22

fSourced from Medicare Geographic Variation 2013.23,24

sSourced from Part D Prescriber Data 2013 and Open Payments List of Teaching Hospitals.11,21

${ }^{h}$ Sourced from Part D Prescriber Data 2013 and Program Statistics Enrollment Dashboard. ${ }^{11,22}$

LIS = low-income subsidy; MAPD = Medicare Advantage Prescription Drug plan; SD=standard deviation

\section{Analysis}

All selected covariates previously described were included in multivariable linear regression models for each dependent variable. The model for prevalence and adequacy of supply is as follows:

$$
y_{\mathrm{j}}=\alpha+X_{\mathrm{j}} \beta+\varepsilon_{\mathrm{j}}, \text { for } \mathrm{j}=1, \ldots, \mathrm{J}
$$

where $j$ indexes the total counties $\mathrm{J} ; X_{\mathrm{j}}$ is a vector of 28 covariates; and $\beta$ is a $28 x \mathrm{x}$ vector of county-level coefficients. Counties missing data for any covariates were excluded from the final models.

We assessed goodness of fit using $\mathrm{R}$ squared $\left(\mathrm{R}^{2}\right)$ and the Akaike Information Criterion (AIC). To better compare the 
TABLE 2 Statin Prescription Prevalence and Adequacy of Supply Among 2013 Medicare Part D Primary Care and Related Providers

\begin{tabular}{|c|c|c|c|c|}
\hline \multirow{2}{*}{$\begin{array}{l}\text { Variable } \\
\text { Intercept }\end{array}$} & \multicolumn{2}{|c|}{$\begin{array}{c}\text { Statin Prescription Prevalence } \\
\text { Estimate }(95 \% \mathrm{CI})\end{array}$} & \multicolumn{2}{|c|}{$\begin{array}{l}\text { Statin Prescription Adequacy of } \\
\text { Supply Estimate }(95 \% \mathrm{CI})\end{array}$} \\
\hline & -0.011 & $(-0.039$ to 0.017$)$ & -0.010 & $(-0.039$ to 0.019$)$ \\
\hline Proportion black or African American & -0.022 & $(-0.063$ to 0.018$)$ & -0.096 & $(-0.137$ to -0.055$)$ \\
\hline Proportion American Indian or Alaska Native & -0.116 & $(-0.15$ to -0.082$)$ & -0.102 & $(-0.136$ to -0.068$)$ \\
\hline Proportion Asian & 0.020 & $(-0.022$ to 0.063$)$ & 0.029 & $(-0.014$ to 0.072$)$ \\
\hline Proportion Native Hawaiian or Other Pacific Islander & 0.002 & $(-0.03$ to 0.034$)$ & 0.002 & $(-0.031$ to 0.034$)$ \\
\hline Proportion Hispanic or Latino & -0.040 & $(-0.098$ to 0.019$)$ & -0.084 & $(-0.144$ to -0.025$)$ \\
\hline Proportion female & 0.003 & $(-0.032$ to 0.039$)$ & 0.003 & $(-0.033$ to 0.039$)$ \\
\hline Proportion females aged $65+$ years & 0.063 & $(0.02$ to 0.107$)$ & 0.091 & $(0.047$ to 0.135$)$ \\
\hline County median income in dollars & 0.043 & $(-0.011$ to 0.096$)$ & -0.017 & $(-0.072$ to 0.037$)$ \\
\hline Proportion uninsured & -0.164 & $(-0.216$ to -0.112$)$ & -0.202 & $(-0.255$ to -0.15$)$ \\
\hline Proportion unemployed & 0.088 & $(0.049$ to 0.127$)$ & 0.053 & (0.013 to 0.093$)$ \\
\hline Fraction of drug costs prescribed as generic & -0.076 & $(-0.111$ to -0.04$)$ & -0.062 & $(-0.098$ to -0.026$)$ \\
\hline Fraction of drug costs prescribed under a low-income subsidy & -0.157 & $(-0.202$ to -0.112$)$ & -0.276 & $(-0.321$ to -0.23$)$ \\
\hline Fraction of drug costs prescribed under Medicare Advantage plans & 0.094 & $(0.061$ to 0.128$)$ & 0.046 & $(0.012$ to 0.08$)$ \\
\hline Proportion female providers & 0.042 & $(0.005$ to 0.079$)$ & 0.024 & $(-0.013$ to 0.062$)$ \\
\hline Proportion nurses & -0.391 & $(-0.435$ to -0.347$)$ & -0.418 & $(-0.463$ to -0.374$)$ \\
\hline Proportion physician assistants & -0.324 & $(-0.363$ to -0.285$)$ & -0.379 & $(-0.418$ to -0.339$)$ \\
\hline Proportion living in a rural area & 0.073 & (0.025 to 0.121$)$ & 0.051 & (0.002 to 0.099$)$ \\
\hline Proportion aged over 65 years & -0.011 & $(-0.058$ to 0.036$)$ & -0.014 & $(-0.062$ to 0.034$)$ \\
\hline Proportion of non-English speakers & 0.087 & (0.028 to 0.145$)$ & 0.095 & (0.035 to 0.154$)$ \\
\hline Proportion inactive & -0.015 & $(-0.068$ to 0.037$)$ & -0.037 & $(-0.09$ to 0.016$)$ \\
\hline Proportion obese & 0.008 & $(-0.045$ to 0.06$)$ & 0.013 & $(-0.041$ to 0.066$)$ \\
\hline Proportion diabetic & 0.141 & (0.077 to 0.205$)$ & 0.108 & (0.043 to 0.173$)$ \\
\hline Proportion with at least some college & -0.039 & $(-0.091$ to 0.013$)$ & -0.061 & $(-0.114$ to -0.008$)$ \\
\hline Rate of social associations per 10,000 population & -0.075 & $(-0.116$ to -0.033$)$ & -0.063 & $(-0.105$ to -0.021$)$ \\
\hline Medicare Part D enrollment count & -0.073 & $(-0.108$ to -0.037$)$ & -0.069 & $(-0.105$ to -0.033$)$ \\
\hline Average Medicare risk score & 0.238 & (0.192 to 0.283$)$ & 0.174 & $(0.128$ to 0.22$)$ \\
\hline Average distance in miles to nearest teaching hospital & 0.013 & $(-0.017$ to 0.043$)$ & 0.025 & $(-0.005$ to 0.056$)$ \\
\hline Fraction of doctors in dataset over number of Part D enrollees & -0.308 & $(-0.345$ to -0.271$)$ & -0.307 & $(-0.345$ to -0.269$)$ \\
\hline
\end{tabular}

Note: Bold type signifies a statistically significant result (95\% CI excluding 0).

$C I=$ confidence interval.

coefficients of the different covariates with a wide range of variability between predictors, we standardized dependent variables and covariates by subtracting the mean and dividing by $1 \mathrm{SD}$. Therefore, regression coefficients should be interpreted as the association of a 1 SD difference in the covariate with a 1 SD change in the outcome. We conducted all analyses using SAS Enterprise Guide version 6.1 (SAS Institute, Cary, NC).

\section{Results}

Cardiovascular prescription data were available for the 268,473 selected providers in 3,029 counties in the continental United States. Across the 2,994 counties that had 1 or more providers where the number of statin beneficiaries were nonredacted, the mean statin prescription prevalence was 24.1\% (SD 6.3\%), and the mean statin adequacy of supply was 15.3\% (SD 4.4\%). Means and SDs for all variables are given in Table 1.
The regression analyses included 2,986 counties with complete data. The statin prescription prevalence (PR) model had higher $\mathrm{R}^{2}$ and lower AIC values $\left(\mathrm{R}_{\mathrm{PR}}^{2}=0.38\right.$; $\left.\mathrm{AIC}_{\mathrm{PR}}=-1,371\right)$ than the statin prescription adequacy of supply (As) model $\left(\mathrm{R}^{2}{ }_{\mathrm{AS}}=0.36 ; \mathrm{AIC}_{\mathrm{AS}}=-1,296\right)$. Standardized beta coefficients $(\beta)$ and $95 \%$ confidence intervals (CI) for each of the covariates in the 2 models are shown in Table 2

On average, 9.1\% (SD 14.4\%) of county residents were black or African American; 8.8\% (SD 13.3\%) were Hispanic/Latino; and 2\% (SD 6.5\%) were American Indian or Alaska Native. All other variables held equal, a 1 SD (14.4\%) increase in the proportion of black or African Americans within a county was associated with a $-0.096 \mathrm{SD}(95 \% \mathrm{CI}=-0.137$ to -0.055$)$, or a $-0.4 \%$ difference in adequacy of supply. For a typical 2013 U.S. county with approximately 12,000 Medicare Part D beneficiaries, the difference would be approximately 50 fewer full-year prescriptions. A 1 SD increase in the proportion of Hispanic/ Latinos within a county was associated on average with a -0.084 
$\mathrm{SD}(95 \% \mathrm{CI}=-0.144$ to -0.025$)$ difference in the adequacy of supply. A 1 SD increase in the proportion of American Indian/ Alaska Natives was associated with a -0.116 SD $(95 \% \mathrm{CI}=-0.15$ to -0.08$)$ difference in statin prevalence and a -0.102 SD (95\% $\mathrm{CI}=-0.14$ to -0.07 ) difference in adequacy of supply. However, proportion of non-English speakers was associated with higher statin prevalence and adequacy of supply $\left(\beta_{\mathrm{PR}}=0.09 ; 95 \%\right.$ $\mathrm{CI}=0.03$ to $0.15 ; \beta_{\mathrm{AS}}=0.10 ; 95 \% \mathrm{CI}=0.04$ to 0.15$)$.

On average, 50\% (SD 2\%) of all county residents and 55\% (SD 3\%) of county residents aged 65 years and over were female. We found no significant association between the proportion of all county residents who were female with either outcome. However, counties with higher proportions of female residents aged 65 years and over had higher statin prevalence $\left(\beta_{\mathrm{PR}}=0.06 ; 95 \% \mathrm{CI}=0.02\right.$ to 0.11$)$ and adequacy of supply $\left(\beta_{\mathrm{AS}}=0.09 ; 95 \% \mathrm{CI}=0.05\right.$ to 0.14$)$.

Counties with higher proportions of uninsured residents had both lower statin prevalence $\left(\beta_{\mathrm{PR}}=-0.16 ; 95 \% \mathrm{CI}=-0.22\right.$ to $-0.11)$ and adequacy of supply $\left(\beta_{A S}=-0.20 ; 95 \% C I=-0.26\right.$ to -0.15). Counties with higher proportions of Part D drug costs covered under the low-income subsidy (LIS) program also had lower statin prevalence $\left(\beta_{\mathrm{PR}}=-0.16 ; 95 \% \mathrm{CI}=-0.20\right.$ to -0.11$)$ and adequacy of supply $\left(\beta_{\mathrm{AS}}=-0.28 ; 95 \% \mathrm{CI}=-0.32\right.$ to -0.23$)$. In the original scale of the outcome, a 1 SD (14\%) increase in the proportion of Part D drug costs covered under LIS was associated with a $1.2 \%(0.276 \mathrm{SD})$ decrease in statin adequacy of supply. For a county of 12,000 Medicare Part D beneficiaries, the difference would be approximately 141 fewer full-year prescriptions. However, all else being equal, counties with higher unemployment had higher statin prevalence and adequacy of supply ( $\beta_{\mathrm{PR}}=0.09 ; 95 \% \mathrm{CI}=0.05$ to $0.13 ; \beta_{\mathrm{AS}}=0.05 ; 95 \%$ $\mathrm{CI}=0.01$ to 0.09 ). Counties with higher numbers of social organizations per 10,000 population also had lower rates of statin prevalence and adequacy of supply $\left(\beta_{\mathrm{PR}}=-0.08 ; 95 \% \mathrm{CI}=-0.12\right.$ to $-0.03 ; \beta_{\mathrm{AS}}=-0.06 ; 95 \% \mathrm{CI}=-0.11$ to -0.02 ). In addition, counties with higher proportions of residents attending at least some college had lower adequacy of supply $\left(\beta_{\mathrm{AS}}=-0.06 ; 95 \%\right.$ $\mathrm{CI}=-0.11$ to -0.01 ).

Of the covariates potentially associated with medical need, the strongest association with higher statin prescription prevalence and supply adequacy was the average Medicare HCC risk score $\left(\beta_{\mathrm{PR}}=0.24 ; 95 \% \mathrm{CI}=0.19\right.$ to $0.28 ; \beta_{\mathrm{AS}}=0.17 ; 95 \% \mathrm{CI}=0.13$ to 0.22 ). The proportion of county residents with diabetes was also positively associated with higher statin prevalence and adequacy of supply $\left(\beta_{\mathrm{PR}}=0.14 ; 95 \% \mathrm{CI}=0.08\right.$ to $0.21 ; \beta_{\mathrm{AS}}=0.11$; $95 \% \mathrm{CI}=0.04$ to 0.17 ).

Of health services-related covariates, the strongest association with lower prevalence and supply adequacy was the proportion of prescribing providers who are nurses $\left(\beta_{\mathrm{PR}}=-0.39\right.$; $95 \% \mathrm{CI}=-0.44$ to $-0.35 ; \beta_{\mathrm{AS}}=-0.42 ; 95 \% \mathrm{CI}=-0.47$ to -0.37 ). In the original scale of the outcome, a 1 SD (18\%) increase in the proportion of nurses reduces the average adequacy of supply from $15.3 \%$ to $13.4 \%$. Other factors most strongly associated with lower statin prescription prevalence and adequacy of supply were the proportion of prescribing providers who are physician assistants $\left(\beta_{\mathrm{PR}}=-0.32 ; 95 \% \mathrm{CI}=-0.36\right.$ to $-0.29 ; \beta_{\mathrm{AS}}=-0.38 ; 95 \% \mathrm{CI}=-0.42$ to -0.34$)$ and the fraction of statin-prescribing doctors over the number of Part D enrollees $\left(\beta_{\mathrm{PR}, \mathrm{AS}}=-0.31 ; 95 \% \mathrm{CI}=-0.35\right.$ to -0.27$)$. Proportion of residents living in a rural area was associated with higher statin prevalence and adequacy of supply ( $\beta_{\mathrm{PR}}=0.07 ; 95 \% \mathrm{CI}=0.03$ to 0.12 ; $\beta_{\mathrm{AS}}=0.05 ; 95 \% \mathrm{CI}=0.00$ to 0.10 ).

\section{Discussion}

Our results lend support to the hypothesis that counties with higher proportions of nonwhites and Hispanic/Latinos will have lower statin use, particularly when examining supply adequacy. While associations with statin use at the county level are modest in terms of effect sizes, they are not trivial for an ecological study, particularly when the changes are applied to county population sizes.

We did not find support for lower statin use in counties with higher proportions of females; rather we found evidence that counties with higher proportions of county residents aged 65 years and older who are female have higher statin prevalence and supply adequacy. We can examine differences in survival by gender by including the proportion of county residents aged 65 years and older who are female. However, there are no means by which we can control for need within the male and female subpopulations.

We found support for the hypothesis that counties with poorer socioeconomic status had lower statin use. A surprising result was that the proportion of unemployed had a positive association with the outcome variables. This may be due to policy effects of social safety net programs after controlling for the proportion uninsured-variables that were not included in the models. Counties in states allowing for longer periods of unemployment before losing benefit eligibility will have higher proportions of recorded unemployed. If these counties also facilitate health care use, it would result in a positive association.

The most interesting exploratory results relate to provider composition. A negative association between primary care doctors per Part D enrollees and both outcomes is partially explained by a lack of doctor availability. Counties included in the regression without any recorded Part D doctors $(n=77)$ will have zero for the ratio of primary care doctors per Part D enrollees. Yet these counties have nonzero statin prescription prevalence and adequacy of supply, contributing to the negative coefficient.

The strong coefficients for the provider type covariates may have an explanation within provider location. All other variables held equal, counties with higher proportions of prescribing doctors relative to nurses and physician assistants may be areas of greater patient need. Exploring Pearson 
TABLE 3 Comparison of Full and Restricted Models

\begin{tabular}{|c|c|c|c|c|}
\hline Predictor & $\begin{array}{l}\text { Statin Prescription } \\
\text { Prevalence Estimate } \\
\text { (95\% CI), Main } \\
\text { Hypothesis Model }\end{array}$ & $\begin{array}{l}\text { Statin Prescription Rate } \\
\text { Estimate }(95 \% \mathrm{CI}), \\
\text { Main Hypothesis Model }\end{array}$ & $\begin{array}{l}\text { Statin Prescription } \\
\text { Prevalence Estimate } \\
\text { (95\% CI), Full Model }\end{array}$ & $\begin{array}{c}\text { Statin Prescription Rate } \\
\text { Estimate }(95 \% \mathrm{CI}) \\
\text { Full Model }\end{array}$ \\
\hline Intercept & $-0.005(-0.037$ to 0.028$)$ & $-0.002(-0.035$ to 0.031$)$ & $-0.005 \quad(-0.02$ to 0.009$)$ & $-0.005 \quad(-0.02$ to 0.009$)$ \\
\hline Proportion black or African American & $0.045 \quad(0.003$ to 0.088$)$ & $-0.036(-0.079$ to 0.006$)$ & $-0.022(-0.063$ to 0.018$)$ & $-0.096(-0.137$ to -0.055$)$ \\
\hline $\begin{array}{l}\text { Proportion American Indian or Alaska } \\
\text { Native }\end{array}$ & $-0.149(-0.184$ to -0.114$)$ & $-0.150(-0.186$ to -0.115$)$ & $-0.116 \quad(-0.15$ to -0.082$)$ & $-0.102(-0.136$ to -0.068$)$ \\
\hline Proportion Asian & $-0.045(-0.088$ to -0.003$)$ & $-0.027(-0.069$ to 0.016$)$ & $0.020(-0.022$ to 0.063$)$ & $0.029(-0.014$ to 0.072$)$ \\
\hline $\begin{array}{l}\text { Proportion Native Hawaiian or Other } \\
\text { Pacific Islander }\end{array}$ & $-0.039(-0.074$ to -0.003$)$ & $-0.027(-0.063$ to 0.009$)$ & $0.002 \quad(-0.03$ to 0.034$)$ & $0.002(-0.031$ to 0.034$)$ \\
\hline Proportion Hispanic or Latino & $-0.021(-0.064$ to 0.023$)$ & $-0.048(-0.092$ to -0.004$)$ & $-0.040(-0.098$ to 0.019$)$ & $-0.084(-0.144$ to -0.025$)$ \\
\hline Proportion female & $0.142 \quad(0.101$ to 0.183$)$ & $0.157 \quad(0.115$ to 0.198$)$ & $0.003(-0.032$ to 0.039$)$ & $0.003(-0.033$ to 0.039$)$ \\
\hline Proportion females aged $65+$ years & $0.010(-0.027$ to 0.046$)$ & $0.006(-0.031$ to 0.042$)$ & $0.063 \quad(0.02$ to 0.107$)$ & $0.091 \quad(0.047$ to 0.135$)$ \\
\hline County median income in dollars & $0.066 \quad(0.011$ to 0.121$)$ & $0.022(-0.033$ to 0.078$)$ & $0.043(-0.011$ to 0.096$)$ & $-0.017(-0.072$ to 0.037$)$ \\
\hline Proportion uninsured & $-0.039(-0.091$ to 0.014$)$ & $-0.077 \quad(-0.13$ to -0.024$)$ & $-0.164(-0.216$ to -0.112$)$ & $-0.202(-0.255$ to -0.15$)$ \\
\hline Proportion unemployed & $0.226 \quad(0.185$ to 0.266$)$ & $0.189 \quad(0.148$ to 0.23$)$ & $0.088 \quad(0.049$ to 0.127$)$ & $0.053 \quad(0.013$ to 0.093$)$ \\
\hline Fraction of drug costs prescribed as generic & $-0.068(-0.106$ to -0.03$)$ & $-0.041 \quad(-0.079$ to -0.003$)$ & $-0.076(-0.111$ to -0.04$)$ & $-0.062(-0.098$ to -0.026$)$ \\
\hline $\begin{array}{l}\text { Fraction of drug costs prescribed under } \\
\text { low-income subsidy }\end{array}$ & $-0.068(-0.113$ to -0.023$)$ & $-0.215(-0.261$ to -0.17$)$ & $-0.157(-0.202$ to -0.112$)$ & $-0.276(-0.321$ to -0.23$)$ \\
\hline $\begin{array}{l}\text { Fraction of drug costs prescribed under } \\
\text { Medicare Advantage plans }\end{array}$ & 0.185 & $0.133 \quad(0.098$ & $0.094 \quad(0.061$ to 0.128$)$ & $0.046 \quad(0.012$ to 0.08$)$ \\
\hline
\end{tabular}

Note: Bold type signifies a statistically significant result (95\% CI excluding 0).

$C I=$ confidence interval.

correlations within the data, the proportion of doctors was the most positively correlated with both the Part D enrollees $\left(\mathrm{R}_{\mathrm{MD}}=0.19, \mathrm{R}_{\mathrm{N}}=0.03, \mathrm{R}_{\mathrm{PA}}=-0.19\right)$ and the average Medicare risk score $\left(R_{M D}=0.13, R_{N}=-0.13, R_{P A}=-0.07\right)$.

To explore the effect of including the covariates, we ran models inclusive only of variables from the main hypotheses $\left({ }_{\text {мн }}\right)$ for prevalence and adequacy of supply $\left(\mathrm{R}^{2}{ }_{\text {MHPR }}=0.17\right.$; $\left.\mathrm{AIC}_{\mathrm{MHPR}}=-546 ; \mathrm{R}_{\text {MHAS }}=0.15 ; \mathrm{AIC}_{\mathrm{MHAS}}=-487\right)$ and compared the results with the same variables in the full model in Table 3. The full models had higher $\mathrm{R}^{2}$ values, indicating that inclusion of the covariates improves the models. The negative coefficients for the race and class variables tended to increase with the inclusion of the covariates. These increases appear to indicate that the additional covariates were either confounding (such as the average Medicare risk score) or mediating (such as the provider type covariates) the relationship between demographic variables and the outcomes. While data limitations preclude an exact specification of how the additional covariates interacted with race, gender, and class, this may be a fruitful area of future research.

\section{Limitations}

This study carries several limitations. The Medicare Part D data did not encompass a provider's entire practice or even all of a provider's Medicare patients, only patients enrolled in the Medicare Part D prescription program whose use was recorded because claims were processed and recorded by CMS. These beneficiaries comprised $68 \%$ of all Medicare beneficiaries. ${ }^{11,12}$ However, poten- tial claimants may have been lost to low-cost generic programs, and this proportion may vary by county, depending on availability of these programs. The availability of these programs may be associated with some of the factors we considered in the analysis and thus may be a source of confounding.

In addition, we note several technical limitations with the data. Providers who had small numbers of beneficiaries were redacted. To minimize the effects of redaction, we constructed the outcome variables from rows where the number of beneficiaries were nonredacted. While this method excluded some supply information, it prohibited adequacy of supply from artificially exceeding the statin prevalence. CHR source data varied in year of collection. To best align with the Medicare Part D 2013 provider data, we used the CHR 2015 data, with the most 2013 source measures. Unfortunately, the data lacked direct measures of county-level cardiovascular risk. However, we did include other factors likely associated with cardiovascular risk, such as obesity and diabetes. ${ }^{27}$

While the HCC risk score was for Medicare Parts A and B as opposed to Part D specifically, it allowed for some measure of general poor health. Lipid level information, especially including individual-level information in a multilevel analysis, would provide a better assessment of population need to better direct potential interventions, although this work provides a basis for further study. We also note that our measure of distance to the nearest teaching hospital used provider ZIP code centroids instead of address, thereby reducing accuracy. 
Overall, our study design, being observational and ecological, does not permit causal inference between the covariates and outcomes. However, the breadth of the study adds another layer of evidence to smaller-scale individual-level studies. We recognize that our analysis focused on 2013, before a substantial shift in emphasis toward statin usage due to new ACC/ AHA guidelines and the policies of the Affordable Care Act had taken effect. However, this study provides an important baseline against which future changes can be assessed. Additional analyses using later years of Medicare Part D Prescriber Public Use Files and updated county information could assess whether factors associated with SDOH are more or less strongly associated with statin use patterns.

Finally, we note that the outcomes we have analyzed may be insufficient to drive additional investment addressing SDOH. Our outcomes were determined by data availability, and we believe that this study shows how low-cost, publicly available data can be used to identify opportunities for improvement, and such data can be easily updated over time. While no single study is likely to drive investment in $\mathrm{SDOH}$ on its own, our work adds to the evidence needed to prioritize and track improvements in outcomes associated with policies meant to address SDOH.

\section{Conclusions}

Using prescription data rather than the survey data of previous national literature, our study provides confirmatory evidence of race/ethnicity and income findings in the literature of statin prescription differences, demonstrating the continued and increasing importance of considering SDOH in policymaking to eliminate disparities. By using a standardized comparison of covariates in an exploratory analysis, it also shows the importance of including variables related to medical infrastructure, contextual enabling characteristics related to the organization of medical care, in future models of statin prescription differences. ${ }^{9}$ These results suggest that the relationships between provider density, provider mix, and statin prescription be further clarified at a member level. This will help determine the need and efficacy of interventions to reduce potential disparities in statin use.

\section{Authors}

STEPH A. KARPINSKI, MS, and KEVIN A. LOOK, PhD, University of Wisconsin, Madison. DAVID J. VANNESS, PhD, Pennsylvania State University, University Park.

AUTHOR CORRESPONDENCE: David J. Vanness, PhD, Pennsylvania State University, Department of Health Policy and Administration, 501J Donald H. Ford Bldg., University Park, PA 16802. Tel.: 814.863.7333; E-mail: djv76@psu.edu.

\section{DISCLOSURES}

No funding was received for this work. Karpinski reports employment by Aetna, Anthem, and Ingenio-Rx. Vanness reports unrelated consulting fees from CHEORS, Evidera, BMS, Novartis, and Merck. Look has nothing to disclose.

\section{ACKNOWLEDGMENTS}

The authors thank John Mullahy and Patrick L. Remington for their helpful comments and suggestions.

\section{REFERENCES}

1. Centers for Disease Control and Prevention. Heart disease. Updated November 28, 2017. Available at: https:www.cdc.gov/heartdisease/facts.htm. Accessed October 14, 2019

2. U.S. Preventative Services Task Force. Statin use for the primary prevention of cardiovascular disease in adults: US Preventive Services Task Force recommendation statement. JAMA. 2016;316(19):1997-2007.

3. Arnett DK, Blumenthal RS, Albert MA, et al. 2019 ACC/AHA Guideline on the Primary Prevention of Cardiovascular Disease: a report of the American College of Cardiology/American Heart Association Task Force on Clinical Practice Guidelines. J Am Coll Cardiol. 2019;74(10):e177-e232. Available at: https://www.sciencedirect.com/science/article/pii/ S073510971933877X?via\%3Dihub. Accessed October 14, 2019.

4. Johansen ME, Hefner JL, Foraker RE. Antiplatelet and statin use in U.S. patients with coronary artery disease categorized by race/ethnicity and gender, 2003 to 2012. Am J Cardiol. 2015;115(11):1507-12.

5. Nelson K, Norris K, Mangione CM. Disparities in the diagnosis and pharmacologic treatment of high serum cholesterol by race and ethnicity: data from the Third National Health and Nutrition Examination Survey. Arch Intern Med. 2002;162(8):929-35.

6. Condliffe S, Link C, Townsend B. Who receives statins? Variations in physician prescribing patterns for patients with coronary heart disease. Appl Econ Lett. 2010;17(17):1647-52

7. Hanley GE, Morgan S, Reid RJ. Income-related inequity in initiation of evidence-based therapies among patients with acute myocardial infarction. J Gen Intern Med. 2011;26(11):1329-35.

8. Wallach-Kildemoes H, Diderichsen F, Krasnik A, Lange T, Andersen M Is the high-risk strategy to prevent cardiovascular disease equitable? A pharmacoepidemiological cohort study. BMC Public Health. 2012;12:610.

9. Andersen RM, Davidson PL, Baumeister SE. Improving access to care. In: Kominski GF, ed. Changing the U.S. Health Care System: Key Issues in Health Services, Policy, and Management. 4th ed. San Francisco, CA: JosseyBass; 2013:33-69.

10. Stone NJ, Robinson JG, Lichtenstein AH, et al. 2013 ACC/AHA guideline on the treatment of blood cholesterol to reduce atherosclerotic cardiovascular risk in adults: a report of the American College of Cardiology/ American Heart Association Task Force on Practice Guidelines. Circulation. 2014;129(25 Suppl 2):S1-45.

11. Centers for Medicare \& Medicaid Services. Medicare Provider Utilization and Payment Data: Part D Prescriber. 2015. Available at: http://www.cms gov/Research-Statistics-Data-and-Systems/Statistics-Trends-and-Reports/ Medicare-Provider-Charge-Data/Part-D-Prescriber.html. Accessed October 14, 2019

12. Centers for Medicare $\&$ Medicaid Services. Medicare fee-for-service provider utilization and payment data. Part D Prescriber Public Use File: a methodological overview. April 23, 2019. Available at: https://www.cms. gov/Research-Statistics-Data-and-Systems/Statistics-Trends-and-Reports/ Medicare-Provider-Charge-Data/Downloads/Prescriber_Methods.pdf. Accessed October 22, 2019 
13. Lin I, Sung J2, Sanchez RJ, et al. Patterns of statin use in a real-world population of patients at high cardiovascular risk. J Manag Care Spec Pharm. 2016;22(6):685-98. Available at: https://www.jmcp.org/doi/10.18553/ jmcp.2016.22.6.685.

14. American Heart Association. Cardiac medications at-a-glance. 2012. Updated April 13, 2018. Available at: http://www.heart.org/HEARTORG/ Conditions/HeartAttack/\%20PreventionTreatmentofHeartAttack/CardiacMedications_UCM_303937_Article.jsp. Accessed October 22, 2019.

15. Mayo Foundation for Medical Education and Research. Cholesterol medications: consider the options. Retrieved May 21, 2015. Available at: https:// www.mayoclinic.org/diseases-conditions/high-blood-cholesterol/in-depth/ cholesterol-medications/art-20050958. Accessed October 22, 2019.

16. U.S. Census Bureau. Geography program. 2010 ZIP Code Tabulation Area (ZCTA) Relationship Files. Retrieved November 5, 2016. Available at: https:// www.census.gov/programs-surveys/geography/technical-documentation/ records-layout/2010-zcta-record-layout.html. Accessed October 22, 2019.

17. Texas A\&M University Geoservices. 2016. Available at: http://geoservices.tamu.edu. Accessed October 22, 2019.

18. County Health Rankings \& Roadmaps. 2015 County health rankings data, v.3. University of Wisconsin Population Health Institute. 2015. Available at: https://www.countyhealthrankings.org/sites/default/files/2015\%20County\%20 Health\%20Rankings\%20Data\%20-\%20v3.xls. Accessed October 22, 2019.

19. County Health Rankings \& Roadmaps. County health rankings 2015: codebook for analytic datasets. University of Wisconsin Population Health Institute. Available at: https://www.countyhealthrankings.org/sites/default/ files/2015\%20Analytic\%20Documentation.pdf. Accessed October 22, 2019.

20. U.S. Census Bureau. American FactFinder. 2009-2013 5-year American Community Survey: Table b01101: sex by age. 2017. Available at: https:// factfinder.census.gov/faces/nav/jsf/pages/using_factfinder.xhtml. Accessed October 14, 2019.
21. Centers for Medicare \& Medicaid Services. Open payments list of teaching hospitals. October 1, 2013. Available at: https://www.cms.gov/ OpenPayments/Downloads/2014-Open-Payments-Cycle-Teaching-HospitalList-[October-2013].pdf. Accessed October 14, 2019.

22. Centers for Medicare \& Medicaid Services. CMS program statistics 2013: Medicare Enrollment Dashboard Data File. 2016. Available at: https:// www.cms.gov/Research-Statistics-Data-and-Systems/Statistics-Trends-andReports/CMSProgramStatistics/Downloads/Enrollment_Dashboard_Data_ File.zip. Accessed October 14, 2019.

23. Centers for Medicare \& Medicaid Services. Medicare Geographic Variation. Public Use File. 2016. Available at: https://www.cms.gov/ Research-Statistics-Data-and-Systems/Statistics-Trends-and-Reports/ Medicare-Geographic-Variation/GV_PUF.html. Accessed October 14, 2019.

24. Centers for Medicare $\&$ Medicaid Services. Medicare data for the geographic variation public use file: a methodological overview. January 2016 update. Available at: https://www.cms.gov/Research-Statistics-Data-andSystems/Statistics-Trends-and-Reports/Medicare-Geographic-Variation/ Downloads/Geo_Var_PUF_Methods_Paper.pdf. Accessed October 14, 2019.

25. Owens IPF. Sex differences in mortality rate. Science. 2002;297(5589): 2008-09.

26. County Health Rankings \& Roadmaps. Social associations. University of Wisconsin Population Health Institute. 2017. Available at: http://www.countyhealthrankings.org/measure/social-associations. Accessed October 14, 2019.

27. National Cholesterol Education Program (NCEP) Expert Panel on Detection, Evaluation, and Treatment of High Blood Cholesterol in Adults (Adult Treatment Panel III). Third report of the National Cholesterol Education Program (NCEP) Expert Panel on Detection, Evaluation, and Treatment of High Blood Cholesterol in Adults (Adult Treatment Panel III): final report. Circulation. 2002;106(25):3143-421. 